\title{
H7N9 bird flu: emerging of psychological problem
}

\author{
Gripe aviária H7N9: emergência e problemas psicológicos
}

Sir, emerging of H7N9 bird flu in this year (2013) is an important health problem ${ }^{1}$. Following the emerging of this infection, there are many interesting relating psychological problem that emerge. In fact, in any previous emerging influenza, the psychological problem is very important ${ }^{2}$. First, the "fear" of this disease is widespread. After its first outbreak in China, many Chinese become panic and this becomes a big psychological problem. In fact, the similar situation can be seen in many previous outbreaks of new influenza ${ }^{3,4}$. Lau et al. noted for the occurrence of this problem in any new emerging influenza and proposed that "Dissemination of accurate, timely information would reduce unnecessary distress and unwanted behaviors"' Second, the problem of psychological problem that can relate to the treatment of the infection should be mentioned. The oseltamivir, which is the drug of choice for treatment, has many side effects including the psychological disorders. Delirium can be induced and this might be difficult to discriminate from the delirium that is caused by the infection ${ }^{5}$. However, Casscells et al. reported that there is no "increased the risk of adverse neuropsychiatric outcomes" ${ }^{10}$ in the influenza infected patients receiving oseltamivir therapy.

Joob Beuy', Wiwanitkit Viroj ${ }^{2}$

\section{References}

1. Wiwanitkit V. H7N9 Influenza: the emerging infectious disease. N Am J Med Sci 2013;5:395-398.

2. Wiwanitkit V. Emerging influenza and psychosis: an important story in psychological medicine. Indian J Psychol Med 2013;35:222-223.

3. Lau JT, Kim JH, Tsui H, Griffiths S. Perceptions related to human avian influenza and their associations with anticipated psychological and behavioral responses at the onset of outbreak in the Hong Kong Chinese general population. Am J Infect Control 2007;35:38-49.

4. Lau JT, Griffiths S, Choi KC, Tsui HY. Avoidance behaviors and negative psychological responses in the general population in the initial stage of the H1N1 pandemic in Hong Kong. BMC Infect Dis 2010;10:139.

5. Kruker AT, Krause M. Oseltamivir-induced delirium. Ther Umsch 2010;67:613-615.

6. Casscells SW, Granger E, Kress AM, Linton A. The association between oseltamivir use and adverse neuropsychiatric outcomes among TRICARE beneficiaries, ages 1 through 21 years diagnosed with influenza. Int J Adolesc Med Health 2009;21:79-89. 